\title{
METHODS
}

\section{The income-environment relationship: Evidence from a binary response model}

\author{
Tom Verbeke $^{a, b, *}$, Marc De Clercq ${ }^{a}$ \\ ${ }^{a}$ Centre for Environmental Economics and Environmental Management, Ghent University, Hoveniersberg 24, 9000 Ghent, Belgium \\ ${ }^{b}$ VLEKHO, Koningsstraat 336, 1030 Brussels, Belgium
}

\section{A R T I C L E I N F O}

Article history:

Received 18 September 2003

Received in revised form

20 September 2005

Accepted 3 November 2005

Available online 18 January 2006

Keywords:

Environmental Kuznets curve

Income-environment relationship

Environmental damage

Binary response

Political equality

Openness

\begin{abstract}
A B S T R A C T
The empirical environmental Kuznets curve (EKC) literature is vast but far from conclusive. Many authors have analysed the existence of an EKC for various pollutants. Others have used the EKC framework to identify country characteristics that help to explain the incomeenvironment relationship. In this framework environmental degradation is analysed using a second or third order polynomial in income and a limited number of control variables. Some authors question whether this standard framework is appropriate. This paper proposes an alternative to study the specific characteristics of countries that have experienced economic growth and an improving environment at the same time. We estimate a binary response model and find an EKC-like relation between the probability that a country's environment improves with economic growth and per capita GDP. Our evidence further suggests that the level of environmental damage is an important explanatory variable. We also confirm the importance of an open political system. These results indicate that the binary response model could be a valuable alternative to test which country specific characteristics are associated with a negative IER.
\end{abstract}

C 2005 Elsevier B.V. All rights reserved.

\section{Introduction}

The environmental Kuznets hypothesis (EKC) predicts an inverse U-shaped relationship between environmental pollution on the one hand and per capita income on the other. This shape is due to the scale-, composition-, income- and technique effect. At first, the increasing scale of economic activity as well as its changing composition from agricultural towards industrial activities generates more pollution. However, as income rises, demand for environmental quality increases and governments introduce more stringent environmental regulation. This income effect, the replacement of old technologies by environmentally less harmful ones, together with the changing composition away from an industrial towards a post-industrial economy puts downward pressure on pollution. Eventually, as income passes some threshold level, better techniques, an increased demand for environmental quality and the composition effect outweigh the scale effect and environmental quality increases with growth.

The standard empirical EKC literature captures the scale-, composition-, income- and technique effects through reduced form regressions (Stern, 1998; de Bruyn et al., 1998) with a proxy for environmental pollution as dependent variable and income, income-squared and often income cubed as independent variables (e.g. Holtz-Eakin and Selden, 1992; Selden and Song, 1994; Shafik, 1994; Grossman and Krueger, 1995; Stern and Common, 2001; Harbaugh et al., 2002).

\footnotetext{
* Corresponding author. Centre for Environmental Economics and Environmental Management, Ghent University, Hoveniersberg 24, 9000 Ghent, Belgium. Tel.: +32 926435 78; fax: +32 92643599.

E-mail address: Tom.Verbeke@UGent.be (T. Verbeke).
} 
We will not attempt to review the complete EKC literature as it is beyond the scope of this paper. However, as Galeotti and Lanza (2005) note, a few common features are shared by most studies on the EKC and are of interest to our paper. The basic empirical analysis of the EKC starts from an estimate of (a variation of)

$e_{i t}=\delta_{i}+\beta_{1} y_{i t}+\beta_{2} y_{i t}^{2}+\beta_{3} z_{i t}+\varepsilon_{i t}$

with $e_{i t}$ a proxy for environmental pollution, $\delta_{i}$ a country specific effect, $y_{i t}$ per capita income, $z_{i t}$ a vector of additional explanatory variables and $\varepsilon_{i t}$ an error term. The subscripts $i$ refer to a cross-section and the subscript $t$ to time. The EKC hypothesis requires that $\beta_{1}>0$ and $\beta_{2}<0$.

The first common feature is related to the functional form. The most commonly used functional form relates a measure of environmental pollution to per capita income, per capita income-squared and often cubed. However, if per capita income cubed is included in the specification, the analysis often ignores the estimate. These equations possibly include a number of extra variables ( $z_{i t}$ in (1)) to capture alternative nonincome related influences on pollution such as the level of trade openness (see for instance Suri and Chapman, 1998), a measure of environmental damage (see for instance Kaufmann et al., 1998) or income or political equality as extra explanatory variables (see for instance Torras and Boyce, 1998).

Secondly, most of the work uses data in levels in a panel setting allowing for cross-section specific fixed or random effects. This implies that Eq. (1) is estimated using time series data for a number of different cross-sectional units such as countries, regions or cities.

Thirdly traditional EKC estimates assume homogeneity in the slope coefficients. In terms of Eq. (1), the estimates of the $\beta$ coefficients are assumed to be identical. Hence, estimates of Eq. (1) predict that an increase in per capita income will have the same impact on environmental pollution in each country or region in the sample.

Fourthly, implicit in most of the work is the hypothesis that the causality runs from income to emissions. In other words, estimates of Eq. (1) assume that emissions do not affect per capita income.

Some authors question the use of this standard EKC empirical strategy. They claim that there are a number of methodological and conceptual problems associated with each of the four common features of the standard EKC empirical framework which we have discussed. Although there are more problems associated with the EKC (see Stern, 1998), we will focus on those related 4 features common to the standard empirical framework.

Let us first turn to the functional form. The EKC's inverted $\mathrm{U}$-shaped relationship between emissions and income implies that at one point in time, environmental pollution will eventually turn negative. Including income cubed or using logarithmic dependent variables (Stern, 1998) solves this problem. However, both solutions can be questioned. Although the third order polynomial in per capita income would only reveal an inverted U-shaped path between emissions and income if income cubed is insignificant, the evidence seems to suggest that this is generally not the case. Grossman and Krueger (1995) for instance find an N-shaped EKC. However, due to the fact that the second income turning point is out of their sample range, they do not put much emphasis on the possibility that emissions could increase with income after a period where the opposite has occurred. Most authors have followed this practice and largely ignored a significant estimate for income cubed. However, the presence of a significant estimate for per capita GDP cubed, i.e. an N-shaped EKC, implies that emissions will rise indefinitely once the trough income level is reached. This seems to be at odds with the EKC-hypothesis. If popular demand is one of the forces that puts downward pressure on environmental pollution, it seems to be contradictory to assume that it will not continue to play its role once income has passed its through level. One can further question the interpretation of a significant estimate for income cubed. Moomaw and Unruh (1997) argue for instance that a significant cubic term in per capita GDP is the result of data aggregation. If this is the case, a significant estimate for this cubic term casts doubt on the proper interpretation of the other income variables.

A second series of critiques involves the use of data in levels. In the environmental field, the evidence so far seems to indicate that a lot of environmental time series are nonstationary time series and are integrated of order 1 (I(1)) or 2 (I (2)). Stern and Kaufmann (1999) for instance analyse the order of integration of time series for $\mathrm{CO}_{2}, \mathrm{SO}_{2}, \mathrm{CH}_{4}, \mathrm{CFC11}, \mathrm{CFC12}$, $\mathrm{N}_{2} \mathrm{O}$ emissions using 4 different tests. Each of their 4 tests confirm that $\mathrm{SO}_{2}$ emissions are $\mathrm{I}(1)$ while 3 out of 4 tests indicate that $\mathrm{CH}_{4}$ and $\mathrm{N}_{2} \mathrm{O}$ are integrated of order 1 . Their evidence further suggests one cannot accept the hypothesis that $\mathrm{CO}_{2}$ is not $\mathrm{I}(1)$ as 2 out of 4 tests point in this direction.Lee and List (2004) show that their US per capita $\mathrm{NO}_{x}$ emissions series for 1900-1994 is I(1). Perman and Stern (2003) perform both individual and panel unit root tests for $\mathrm{SO}_{2}$ emissions and per capita GDP for 74 countries using 30 years of data. They conclude that both these variables are integrated in the majority of countries. Bertinelli and Strobl (2005) confirm these results for per capita GDP, sulphur and carbon dioxide emissions. This suggests that it is not unreasonable to assume that many environmental series used to test the EKC are I(1). However, as Nelson and Plosser (1982) found, a lot of economic time series such as per capita income are also integrated. Lee and List (2004) argue that most of the studies do not take into account the time series properties of the data. The use of variables in level in a panel data setting requires the assumption that these variables are stationary or, if that is not the case, that there is a cointegrating relationship among per capita emissions and the income terms. As argued by Stern and Common (2001), estimates obtained from reduced form regressions in levels of pollution and per capita GDP might be spurious if there is no cointegration relation among these variables. Perman and Stern's (2003) results provide evidence that there is no such common cointegrating vector for $\mathrm{SO}_{2}$ emissions. Furthermore, a Monte Carlo exercise discussed in Verbeke and De Clercq (in press) suggests that the standard EKC framework spuriously produces the EKC results if integrated series are used in over $40 \%$ of the cases.

With respect to the second feature, there is a second argument that questions the use of the standard EKC framework. Halkos and Tsionas (2001) argue that the use of OLS to estimate equations such as (1) is inappropriate if two 
distinct regimes govern the income environment relationship. They propose a switching regime model and report results for carbon dioxide and deforestation. Their results cast doubt on the existence of an EKC. Aslanidis and Xepapadeas $(2003,2004)$ also use this approach to model the emission-income relationship. Their evidence suggests that there are two regimes and they confirm the EKC hypothesis.

With respect to the assumed homogeneity in the slope coefficients, there is a lot of evidence that suggests that this assumption does not hold in practice. List and Gallet (1999) for instance find a wide variety of slope coefficients for their panel of US states. Hence, OLS estimates will be biased and inconsistent if the non-homogeneity is not accounted for.

With respect to the fourth common feature of the empirical work, i.e. that the causality runs from income to emissions, there has been some evidence that suggests that this does not need to be the case. Indeed, Coondoo and Dinda (2002) produce evidence which suggests that for carbon dioxide emissions, causality might run in the opposite direction. Furthermore, their work indicates that causality might run both ways. If that is the case the standard EKC empirical strategy does not account for simultaneity and produces biased and inconsistent estimates Stern (1998). However, as noted in, for instance, List and Gallet (1999) or Lieb (2004) simultaneity bias does not seem to be an important issue. List and Gallet (1999) for instance cannot reject the hypothesis that per capita GDP is exogenous for their dataset with $\mathrm{SO}_{2}$ and $\mathrm{NO}_{\mathrm{x}}$ emissions of US states. This problem can be an important one for other pollutants such as carbon dioxide emissions.

Given these issues, this paper uses an alternative strategy. In the next section, we propose a binary response model which we will use in the third section to check for EKC-like patterns in the income-environment relationship (IER) for sulphur dioxide emissions $\left(\mathrm{SO}_{2}\right)$. Furthermore, we use the model to test the influence of environmental damage, the level of democracy and openness on the probability that a country experiences a period of positive economic growth and improving environmental conditions. The last section concludes.

\section{A binary response model to test the IER}

The short review in the previous section suggests that it is worthwhile to investigate a country's IER with an alternative empirical model that suffers less from the methodological issues and allows researchers to examine both the IER to test for an EKC pattern as well as the role of other mechanisms that shape the IER. We start from the observation that the slope of the EKC, $\partial e_{i t} / \partial y_{i t}$, can be positive or strictly negative (see Eq. (1)). As noted in Aslanidis and Xepapadeas (2003) the sign of the slope can be associated different 'states of the world' or regimes. If $\partial e_{i t} / \partial y_{i t} \geq 0$ economic growth does not cause an improvement in environmental quality. If, on the other hand $\partial e_{i t} / \partial y_{i t}<0$, environmental quality improves with rising income. The EKC hypothesis implies that the IER switches regimes in a given country if per capita income passes some threshold level.

Let $\Delta e_{i t}$ denote the change in environmental pollution in country $i$ during period $t$ to $t+j$ and $\Delta y_{i t}$ the change in per capita income for country $i$ during the same period $t$ to $t+j$. If $\Delta e_{i t} /$ $\Delta y_{i t}<0$ country i's economy grew (experienced a recession) over period to $t+j$ as $\Delta y_{i t}>0\left(\Delta y_{i t}<0\right)$ while pollution dropped (increased) over the same period: $\Delta e_{i t}<0\left(\Delta e_{i t}>0\right)$. If that is the case, one can say that country i's IER was (strictly) negative from $t$ to $t+j$ as more (less) economic activity went hand in hand with less (more) pollution. In our empirical implementation we have chosen not to include the periods where $\Delta y_{i t}<0$ and $\Delta e_{i t}>0$ because those are likely to introduce 'a-typical' observations to our set of negative IER's. It could, for instance, be possible that during periods of war negative economic growth is associated with more pollution due to military activities. If $\Delta e_{i t} / \Delta y_{i t} \geq 0$ country i's IER was positive from $t$ to $t+j$. These two states of a country's IER are mutually exclusive. Hence, we can define the binary variables $I_{i t}$ as

$I_{\text {it }}=\left\{\begin{array}{l}1 \Leftrightarrow \Delta e_{i t}<0 \text { and } \Delta y_{i t}>0 \\ 0 \text { otherwise }\end{array}\right.$.

If $I_{i t}=1$ country $i$ 's IER was (strictly) negative from $t$ to $t+j$. If $I_{i t}=0$ its IER was positive over that time period or the period was considered a-typical.

We can model the probability that we find that environmental pollution is decreasing as income grows, by the binary response model

$\operatorname{Pr}\left[I_{i t}=1 \mid x_{i t}\right]=f\left(x_{i t} \beta\right)$

where $f$ is a distribution function, $x_{i t}$ is a matrix of the independent variables for country $i$ and period $t$ and $\beta$ is a vector of parameters to be estimated. A test of the EKC requires that the independent variables include both $y_{i t}$ and $y_{i t}^{2}$. Furthermore, the estimates of the parameters associated with these per capita income variables should suggest that $\operatorname{Pr}\left[I_{i t}=1 \mid\right.$ $x_{i t}$ ] decreases at early stages of economic development and increases after per capita income surpasses some threshold. If the estimates fail to allow that conclusion, it would be hard to argue that the IER follows and EKC-type of path.

As noted in Estrella and Mishkin (1997) the construction of a binary variable implies that one abstracts from the magnitude of the change in the dependent variable caused by a change in one of the independent variables and one focuses on a simple binary indicator. Instead of focussing on 'how much' emissions decrease as income grows, a binary indicator analyses 'if' that has been the case. Although one can argue that these models are less precise as they are unable to determine the actual magnitude, they are less demanding which may increase their potential accuracy (Estrella and Mishkin, 1997).

The fact that they are less demanding offers some perspective in terms of the critiques on the standard empirical EKC framework. Indeed, the binary response approach seems to suffer less from the criticisms discussed in the Introduction.

First of all, a binary response approach is more flexible with respect to the shape IER. Even if we include per capita income and its square in the model as independent variables, it does not force an inverted U- or N-shaped IER. Assume that the estimates are such that model would predict that the probability of a negative IER decreases for low levels of per capita income and increases after income reaches a threshold. With the exception of those countries for which the estimates 
mean that $\operatorname{Pr}\left[I_{i t}=1 \mid x_{i t}\right]=1$ such a finding does not imply the IER will be negative for each and every period for which per capita income is higher than the threshold. As a matter of fact, the model explicitly allows for periods characterized by a negative IER to be followed by a period with a positive one. It seems to be important to allow for such a possibility. Assume for instance that demand for a better environmental quality depends on both income as well as the level of environmental damage (see Kaufmann et al., 1998 for a discussion). The disutility caused by pollution does not only depend on the level of income, but also on the level of damage to the environment due to pollution. Assume also that government policy is introduced or changed at specific, discrete points in time when the public is concerned enough about the damages and demands government intervention (see the model by Smulders and Bretschger, 2001). Thirdly, assume that government policy has only a transitory effect on pollution. As noted by Lee and List (2004) this implies that government intervention does not have an influence on long run pollution trends. Government policy causes a downward shift in the level of pollution but the growth rate will revert to its mean. With these assumptions, it is easy to sketch a scenario where the slope of the IER alternates between negative and positive. If the level of damage caused by environmental pollution is sufficiently high, popular demand for a better environmental quality causes government intervention. In the period following the intervention, pollution drops as economic agents adapt their behaviour to the new legislation. If, over that same period per capita income has grown, the IER was negative. However, as the effect of the intervention is only transitory, pollution growth rates return to their long run path and if per capita income continues to grow, the IER will be positive. Obviously, at one point in time, environmental pollution will return to a level where it causes a sufficient amount of damage and governments are again required to intervene. A binary choice model allows for such behaviour, whereas the traditional inverted-U of $\mathrm{N}$ shaped EKC does not.

A binary response model does not suffer from the methodological issues related to the time series properties of the data as the dependent variable is a binary indicator.

A third series of critiques concerned the assumed homogeneity of the slope of an EKC-type of IER: an increase in per capita income causes the same drop in per capita emissions in every country or region included in the analysis. A binary response model is less demanding in that respect. First of all, the construction of the binary indicator $I_{i t}$ does not include a criterion which includes the size of the change in environmental pollution. Furthermore, from (3) it can be seen that a change in per capita income does not have to have an equal impact on $\operatorname{Pr}\left[I_{i t}=1 \mid x_{i t}\right]$ as

$\frac{\partial \operatorname{Pr}\left[I_{i t}=1 \mid x_{i t}\right]}{\partial y_{i t}}=\frac{\partial f\left(x_{i t} \beta\right)}{\partial x_{i t} \beta} \frac{\partial x_{i t} \beta}{\partial y_{i t}}$.

With the exception of the linear probability model, the impact of a change in $y_{i t}$ depends on the values of the other independent variables.

With respect to the causality, we can construct the binary indicator in such a way that the results do not suffer from simultaneity biases. More specifically, in our implementation of the approach, explanatory variables always refer to periods prior to the binary variable indicating if the IER was negative or positive.

Although the model has some advantages, there are some disadvantages as well. The first one concerns the ability to calculate the level of environmental pollution at the peak. We have already referred to the fact that a binary response approach abstracts from the magnitude of a variable. Hence, from its results, it is impossible to conclude whether this peak level causes irreversible harm or not. As Arrow et al. (1995) have pointed out, if pollution at the peak cause irreversible harm, there will be no level of income that can correct for the harm done to the environment.

Secondly, a binary response model is binary and it does not allow distinguishing between those observations that point to a 'very negative' IER, a 'moderately negative' IER and a 'somewhat negative' IER. Although a multinomial approach could come to the rescue, it does require the researcher to determine the boundaries between 'very', 'moderately' and 'somewhat'.

We have already pointed out that the binary response approach offers some evidence with respect to the question if a country's IER follows and EKC-type of path. The evidence is indirect as the estimates cannot confirm an EKC-type of IER. However, it could provide evidence against the EKC. If $I_{i t}=1$, the environment improves with economic growth. The estimates of the binary response model would offer evidence against the EKC if there is no level of income below which economic growth is associated with a lower probability of a negative IER and above which it is associated with a higher probability of a negative IER.

\section{Empirical model and data}

Implementing a binary response approach requires 3 decisions. First, we need to define $I_{i t}$, i.e. determine when $\Delta e_{i t}<0$ and $\Delta y_{i t}>0$. Secondly we have to specify $f$. Thirdly we have to determine which variables to include in $x_{i t}$.

With respect to the first choice, we have used data for $\mathrm{SO}_{2}$ emissions as our measure of environmental pollution. We used this pollutant for two reasons. First of all, it is a pollutant that has been widely used in empirical EKC literature. Secondly, $\mathrm{SO}_{2}$ data is available for a large number of countries as well as years. $\mathrm{SO}_{2}$ emissions are from A.S.L. and Associates (Lefohn et al., 1999). As is usual in the EKC literature, population is used to normalize emissions. Population data was taken from the Penn World Tables (Mark 5.6a, Summers and Heston, 1994).

We have used the 2 rules to establish if a country's environment improves with higher levels of income, i.e. if $I_{i t}=1$ We have tried to keep them as simple albeit as realistic and close to the EKC as possible. Our first rule uses per capita emissions and per capita GDP for 5-year periods. As a base year, we use $t=1960,1965,1970,1975,1980$ and 1985. For country $i$ and base year $t I_{i t}=1$ if 3 conditions are simultaneously met. In the 5-year period following the base year (1) per capita GDP must have increased (i.e. $y_{i t+5}>y_{i t+1}$ ), (2) per capita emissions must have fallen $e_{i t+5}<e_{i t+1}$ and (3) we require that total emissions $(E)$ in the first year of the 5 -year period are lower than total emissions in the last year, i.e. $E_{i t+5}<E_{i t+1}$. 
We have chosen to work with non-overlapping 5-year periods 1961-1965, 1966-1970, 1971-1975, 1976-1980, 19811985 and 1986-1990 to avoid the problem of autocorrelation.

We respect the choice of the 5 -year period, we have done so to acknowledge the fact that the process of policy formulation and implementation takes time. As noted in Lieb (2004) if environmental policy is one of the driving forces behind the IER, one has to take into account the fact that regulations have to be drafted, voted and implemented. Hence there is a time lag between the conditions in the base year and the actual impact on emissions. The use of 5-year periods accounts for this lag. Obviously, the use of 5-year periods is somewhat arbitrary. To test the robustness of our results for the choice of the timeframe, we checked with an alternative indicator which uses 10-year periods for the base years $t=1960,1970$ and 1980 and 10-year intervals 1961-1970, 1971-1980 and 1981-1990. The requirements with respect to per capita income, per capita emissions and total emissions are similar and defined over 10-year periods. We will refer to the '10-year rule' if we use data based on these 10-year periods and to the '5-year rule' if we use data based on the 5-year periods.

We have chosen to use only the base years to estimate the binary response model. This leaves 440 observations for the 5 year rule and 220 observations for the 10-year rule.

Table 1 summarizes these rules.

From Table 1, it can be seen that we have $23 \%$ out of a total of 440 5-year periods where countries are experiencing improved environmental quality as well as economic growth. The 10 -year rule reveals $21 \%$ negative slopes out of a total of 220 observations. Observations with a negative IER do not all come from 'rich' countries although the majority of them do. For OECD members for instance, 36\% out of a total of 138 observations show a negative IER. The relative number of negative IER's differs somewhat between the two rules. However, they seem to be comparable.

With respect to $f$ in (3) we have chosen to use 2 alternatives which allow us to test our results for the robustness of our choice of $f$. The first one is the cumulative logistic distribution function. With country specific fixed effects, this yields the fixed effects logit model:

$\operatorname{Pr}\left[I_{i t}=1 \mid x_{i t}, \alpha_{i}\right]=\frac{\exp \left(x_{i t} \beta+\alpha_{i}\right)}{1+\exp \left(x_{i t} \beta+\alpha_{i}\right)}$

where $\alpha_{i}$ is the country specific fixed effect. Eq. (5) is estimated using the conditional maximum likelihood method (Maddala,

Table 1 - Total number of observations and negative IER

\begin{tabular}{lrrrrr} 
& \multicolumn{2}{c}{5 -year rule } & & \multicolumn{2}{c}{ 10-year rule } \\
\cline { 2 - 3 } \cline { 5 - 6 } \cline { 5 - 6 } Total & Obs. & Neg. IER (\%) & & Obs. & Neg. IER (\%) \\
Western Europe & 114 & 23 & & 220 & 21 \\
Eastern Europe & 24 & 40 & & 57 & 36 \\
North America & 48 & 15 & & 12 & 8 \\
South America & 48 & 13 & & 24 & 13 \\
Africa & 90 & 19 & & 45 & 13 \\
Asia & 104 & 20 & & 52 & 17 \\
Oceania & 12 & 33 & & 6 & 33 \\
OECD & 138 & 36 & & 69 & 33
\end{tabular}

a Obs. refers to the total number of observations. Neg. IER refers to those observations for which the IER is negative.
1987). The country specific constants are not reported. We have used the conditional logistic regression (xtlogit) command in STATA.

A major drawback from the conditional maximum likelihood logistic regression is that only countries for which $I_{i t}$ actually switches are included in the estimation. In our analysis, this means that countries who have never experienced a downward sloping IER or who have always been on its downward sloping path are excluded from the estimation. A random effects specification does not suffer from this drawback. However, as noted in Maddala (1987) a major disadvantage of the multivariate logistic distribution is that is restricts all correlations to $1 / 2$. As the error term in random effects estimates is correlated across cross-sections, the multivariate logistic distribution does not allow much flexibility. The probit model is much more flexible in that respect which is why we also estimated a random effects probit model

$\operatorname{Pr}\left[I_{i t}=1 \mid x_{i t}, v_{i}\right]=\Phi\left(x_{i t} \beta+v_{i}\right)$

where $v_{i}$ are iid $N\left(0, \sigma_{v}^{2}\right)$ country specific random effects and $\Phi$ is the cumulative normal distribution. However, the random effects model assumes that $x_{i t}$ and $v_{i}$ are uncorrelated. This might be a strong assumption. We use sTATA's xtprobit command to estimate the random effects probit model.

EKC literature inspired the explanatory variables that are included in $x_{i t}$ : the log of per capita income and its square, environmental damage (Kaufmann et al., 1998), an indicator of political equality (see Torras and Boyce, 1998; Magnani, 2000; Ravallion et al., 2000) and an indicator of openness to international trade. We have added environmental damage because standard EKC models could be misspecified in the absence of such an indicator. Indeed, as Kaufmann et al. (1998) for instance suggest, the marginal benefit of an improved environment is an important variable that is missing in a lot of the work on the EKC. Assuming that marginal benefits of less pollution are higher if the concentration of an environmental pollutant is higher; they include a measure of benefits of better environmental quality and find that the inverted U-shape between pollution and per capita income disappears. From their evidence, these authors conclude that income as such is not sufficient to explain the downward sloping part of the EKC and a measure of benefits should be included. Stern (2005) also suggests that countries with higher levels of emissions per unit area could be more aggressive in adopting pollution abating technologies. We measure environmental damage as the log of the size of a country (measured in square kilometres) per ton of $\mathrm{SO}_{2}$ emissions. Area data are from the World Development Indicators (World Bank). This measure assumes that damage from emissions will be higher if these emissions are located in a smaller area. A major drawback of this definition of concentration is the fact that sulphur emissions are internationally mobile and measured concentrations in one country might be different from the concentrations as calculated here. This is especially the case with respect to sulphur dioxide, which is a non-uniformly mixing pollutant (see Folmer and de Zeeuw, 2000). Secondly, as an indicator of environmental harm, emissions do not take into account the capacity of the natural environment to absorb them. The number of square kilometres a ton of $\mathrm{SO}_{2}$ has to spread may thus not fully reflect environmental damage. This could be 
important for some areas if their import/export ratio of sulphur dioxide emissions is highly skewed or if the capacity of the environment is significantly different from the capacity in other countries. However, data on measured concentrations is only available for a subset of our observations.

Heerink et al. (2001) have shown that the degree of income or power inequality should be added due to the fact that standard EKC regressions are based on aggregated concave individual EKC's. Harbaugh et al. (2002) include a democracy index in their EKC regressions and find that it has a negative effect on pollution. Political equality data are from the Polity IV dataset (Marshall and Jaggers, 2000). The major advantage of this dataset is its level of detail and the large coverage in terms of time and geographic scope. To construct the polity variable, the authors use indicators of democracy and autocracy and authority characteristics. These indicators measure issues such as the extent to which the executive or legislative branch of government is open to political parties. With these characteristics, they construct the variable POLITY as a measure of the equality of a political system on a scale from -10 (closed, autocratic political systems) to +10 (open, democratic political systems).

Openness of the economy is calculated as the sum of exports and imports in percent of GDP. Both per capita GDP in 1985 constant USD as well as openness are from the Penn World tables (mark 5.6a, Summers and Heston, 1994).

Table 2 summarizes our data for each rule.

Explanatory variables always refer to the first year prior to the year for which the binary indicator was calculated. If $\Delta e_{i t}=e_{i t+j}-e_{i t+1}$ then all explanatory variables included in $x_{i t}$ are measured in $t$.

For each IER-rule and model we have estimated 5 specifications. With 5 specifications we can test the robustness of our results for each model and rule. The various specifications are variants of:

$$
\begin{aligned}
\operatorname{Pr}\left[I_{i t}=1\right]= & f\left(\delta_{i}+\beta_{1} y_{i t}+\beta_{2} y_{i t}^{2}+\beta_{3} D_{i t}+\beta_{4} P_{i t}+\beta_{5} D_{i t} P_{i t}\right. \\
& \left.+\beta_{6} y_{i t} P_{i t}+\beta_{7} O_{i t}\right)
\end{aligned}
$$

where $\delta_{i}=\alpha_{i}$ in the fixed effects logit model and $\delta_{i}=v_{i}$ in the random effects probit model, $y_{i t}$ is the log of per capita GDP, $D_{i t}$ is environmental damage, $P_{i t}$ is our polity variable and $O_{i t}$ is openness of the economy. The first specification uses only the

\begin{tabular}{|c|c|c|c|c|c|}
\hline & Obs. & Mean & S.D. & Min. & Max. \\
\hline \multicolumn{6}{|l|}{ 5-year rule } \\
\hline Per capita GDP & 440.00 & 3,108 & 2.61 & 316 & 20,018 \\
\hline Concentration $^{\mathrm{a}}$ & 444.00 & 3,582 & 10.97 & 3.11 & $29,453,108$ \\
\hline Polity & 405.00 & 1.35 & 7.92 & -10.00 & 10.00 \\
\hline Openness & 440.00 & 57.95 & 46.19 & 5.00 & 423.41 \\
\hline \multicolumn{6}{|l|}{ 10-year rule } \\
\hline Per capita GDP & 220.00 & 2,945 & 2.61 & 316 & 20,018 \\
\hline Concentration $^{\mathrm{a}}$ & 222.00 & 3,818 & 11.20 & 3.11 & $29,453,108$ \\
\hline Polity & 198.00 & 1.51 & 7.89 & -10.00 & 10.00 \\
\hline Openness & 220.00 & 57.93 & 48.46 & 5.00 & 423.41 \\
\hline
\end{tabular}
per capita income terms and restricts the coefficients

a The large value for the maximum for the variable concentrations refers to Tanzania which has very little $\mathrm{SO}_{2}$ emissions. $\beta_{3}=\beta_{4}=\beta_{5}=\beta_{6}=\beta_{7}=0$. The second specification adds $D_{i t}$ and restricts $\beta_{4}=\beta_{5}=\beta_{6}=\beta_{7}=0$. The third specification adds $P_{i t}$ and imposes $\beta_{5}=\beta_{6}=\beta_{7}=0$. However, as this variable was almost never significant, we introduced a fourth specification which drops $P_{\text {it }}$ but adds, following Magnani (2000), the interaction terms in polity and concentrations $\left(P_{i t}{ }^{*} D_{i t}\right)$ and polity and income $\left(P_{i t}{ }^{*} y_{i t}\right)$. This specification implies that $\beta_{4}=\beta_{7}=0$. We have introduced these interaction terms as a way to capture the notion that a higher popular demand for a better environment for instance because of the income-effect will have a different impact on environmental policies in democracies.

The fifth specification adds $O_{i t}$ to the fourth one and only $\beta_{4}=0$.

\section{Results}

Table 3 reports the results of the fixed effects logit model for the 5 -year rule. Table 4 presents the results for the 5 -year rule random effects probit model. The results for the 10-year rule are available in Tables A1 (fixed effects logit) and A2 (random effects probit) in Appendix A. All tables include the number of observations (N. Obs.) and the number of groups (N. Groups) that were used, the log likelihood of the model (Log Likelihood), the log likelihood of a model which includes only a constant (Log likelihood c.o.) and 2 measures of fit. The first one, $\chi^{2}$-statistic is a measure of the joint significance of all variables in the model. The second one, the Pseudo- $R^{2}$ is calculated as (see Estrella, 1998)

Pseudo- $R^{2}=1-\left[\frac{L(\hat{\beta})}{L(\tilde{\beta})}\right]^{-\left(\frac{2}{n}\right) L(\tilde{\beta})}$

where $L(\hat{\beta})$ is the log likelihood of the estimated model and $L(\tilde{\beta})$ is the log likelihood of the constant only model. To save some space, we do not report the constant from the random effects probit models. All constants were positive and significant at the $5 \%$ or $1 \%$ level of significance.

The results are similar across IER rules. With respect to per capita GDP the estimates reveal a U-shaped relation between per capita income and the probability of a negative IER. The marginal effect of a change in the log of per capita income on the probability that a country is experiencing improving environmental conditions as well as economic growth equals, for the fixed effects logit model

$\frac{\partial \operatorname{Pr}\left[I_{i t}=1 \mid x_{i t}, \alpha_{i}\right]}{\partial y_{i t}}=\frac{\exp \left(x_{i t} \beta+\alpha_{i}\right)}{\left(1+\exp \left(x_{i t} \beta+\alpha_{i}\right)\right)^{2}}\left(\beta_{1}+2 \beta_{2} y_{i t}+\beta_{6} P_{i t}\right)$

and

$\frac{\partial \operatorname{Pr}\left[I_{i t}=1 \mid x_{i t}, v_{i}\right]}{\partial y_{i t}}=\Phi\left(x_{i t} \beta+v_{i}\right)\left(\beta_{1}+2 \beta_{2} y_{i t}+\beta_{6} P_{i t}\right)$

for the random effects probit model.

Eqs. (9) and (10) are positive for specifications $1-3$ if $\beta_{1}+$ $2 \beta_{2} y_{i t}>0$. If $\beta_{1}<0$ and $\beta_{2}>0$ it follows that the marginal impact of an increase in per capita GDP will be positive if $y_{i t}>-\frac{\beta_{1}}{2 \beta_{2}}$. If per capita income exceeds this threshold, the probability of a negative IER increases with income. As long as per capita incomes are smaller, the probability of a negative IER falls as 


\section{Table 3 - Estimates of the fixed effects logit model for the 5-year rule}

(1) (2)

\begin{tabular}{lc}
\hline Per capita GDP & -8.7197 \\
Per capita GDP sq. & 0.5932 \\
Concentration & \\
Polity & \\
Concentration ${ }^{*}$ Polity & \\
Per capita GDP ${ }^{*}$ Polity & \\
Openness & \\
N. Obs. & 294 \\
N. Groups & 49 \\
Log likelihood & -115 \\
Log likelihood c.o. & -120.05 \\
$\chi^{2}$ & $10.1^{* * *}$ \\
Pseudo- $R^{2}$ & 0.0345 \\
Income turning point & \\
Polity $=+10$ & 1556 \\
Polity $=-10$ &
\end{tabular}

(3)
(4)

$\begin{array}{cc}-15.8511[6.2111]^{* *} & -15.8404[6.2137]^{* *} \\ 0.9846[0.3730]^{* * *} & 0.978[0.3739]^{* * *} \\ -1.7994[0.4501]^{* * *} & -1.7908[0.4503]^{* * *} \\ & \\ -0.0509[0.0224]^{* *} & -0.0508[0.0224]^{* *} \\ 0.068[0.0292]^{* *} & 0.0679[0.0291]^{* *} \\ & 0.003[0.0118] \\ 265 & 265 \\ 46 & 46 \\ -85.91 & -85.87 \\ -108.94 & -108.94 \\ 46.08^{* * *} & 46.14^{* * *} \\ 0.1774 & 0.1777 \\ 3132 & 3289 \\ 2218 & 2324 \\ 4424 & 4654\end{array}$

a Dependent variable is the probability that the IER is negative over a 5 -year period. Column headings refer to the specification. Standard errors are reported between brackets. ${ }^{* * *},{ }^{* *}$ and ${ }^{*}$ denote significance at the $1 \%, 5 \%$ and $10 \%$ level.

$\mathrm{b}$ Income turning points are in 1985 USD.

income rises. Hence, if we find that $\beta_{1}<0$ and $\beta_{2}>0$, the evidence would be favourable to the notion that higher incomes are associated with a higher probability of improving environmental conditions. Columns (1)-(3) of Table 3 report the results for specifications 1-3 of the fixed effects logit model using the 5-year rule. The estimates suggest that the probability of a negative IER increases for income levels larger than 1985 USD 1556 to 1985 USD 2931. Similar levels hold across rules. These income levels are within the sample range (see Table 2). These estimates are on the low end of previously reported results (see Table 2.1 in Lieb, 2004), Grossman and Krueger (1995), Panayotou (2000) or Torras and Boyce (1998) have found similar levels for $\mathrm{SO}_{2}$.

The results for specifications 4-5, with the exception of those for the fixed effects logit estimates using the 10-year rule reported in Table A1, provide evidence that suggests that income turning points differ with the level of political openness. Columns (4)-(5) (in Tables 3, 4 and A2) show that the coefficient $\beta_{6}$ for the interaction term in per capita GDP and polity is negative and significant. From Eqs. (9) and (10), one can see that this implies that the probability of a negative IER increases if the log of per capita income is higher than $-\frac{\left(\beta_{1}+\beta_{6} P_{i t}\right)}{2 \beta_{2}}$. The bottom 2 rows of (Tables 3, 4 and A2) show the threshold level of income in two extreme political equality cases. If polity $=10$, which indicates that a country is characterized by very open and democratic political structures, the probability that a country's IER is negative increases with per capita income if the latter is higher than 1985 USD 1485 (column (4) of Table 4) to 1985 USD 3267 (column (4) of Table A2). If, on the other hand, countries are politically closed and autocratic (polity $=-10$ ) this threshold roughly doubles.

These estimates suggest that the probability that a country's IER is negative follows an EKC-type of transition. At low levels of per capita GDP, an increase in income is

Table 4 - Estimates of the random effects probit model for the 5-year rule

\section{(1)}

\begin{tabular}{lcc}
\hline Per capita GDP & $-3.9779[1.3700]^{* * *}$ & $-4.1334[1.40$ \\
Per capita GDP sq. & $0.2706[0.0860]^{* * *}$ & $0.2775[0.08$ \\
Concentration & & $-0.0344[0.04$ \\
Polity & & \\
Concentration ${ }^{*}$ Polity & & \\
Per capita GDP*Polity & & \\
Openness & & 440 \\
N. Obs. & 440 & 74 \\
N. Groups & 74 & -221.48 \\
Log likelihood & -221.81 & -234.4 \\
Log likelihood c.o. & -234.4 & $25.83^{* * *}$ \\
$\chi^{2}$ & $25.17^{* * *}$ & 0.0586 \\
Pseudo- ${ }^{2}$ & 0.0571 & 1716 \\
Income turning point ${ }^{\mathrm{b}}$ & 1556 & \\
Polity=+10 & & \\
Polity $=-10$ & &
\end{tabular}

(3)

(2)
(4)
$0.319[0.0913]^{* * *}$

$-0.0311[0.0440]$

$0.0167[0.0129]$
$-4.86[1.4523]^{* * *}$

$-3.5156[1.4714]^{* *}$
$0.232[0.0931]^{* *}$
$-0.0313[0.0426]$

$-0.0107[0.0042]^{* * *}$
$0.0127[0.0044]^{* * *}$

402

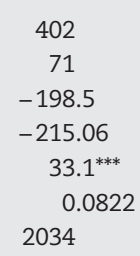

402
71
-195
-215.06
$40.11^{* * *}$
0.0995
1952
1485
2567

(5)

$-3.1855[1.3092]^{* *}$
$0.21[0.0828]^{* *}$
$-0.0043[0.0396]$

$-0.0108[0.0038]^{* * *}$
$0.0129[0.0041]^{* * *}$
$0.0025[0.0017]$
402
71
-194.29
-215.06
$41.54^{* * *}$
0.1030
1968
1447
2675

a Dependent variable is the probability that the IER is negative over a 5 -year period. Column headings refer to the specification. Standard errors are reported between brackets. ${ }^{* * *},{ }^{* *}$ and ${ }^{*}$ denote significance at the $1 \%, 5 \%$ and $10 \%$ level.

b Income turning points are in 1985 USD. 
associated with a reduction in the probability that a country's environment improves with economic growth. However, once per capita GDP reaches an income level equal to the reported turning points, this probability increases with per capita GDP. The thresholds are affected by the political openness of a country. This suggests that demand for a better environment is translated into environmental policy action sooner, i.e. at lower levels of per capita income, in politically open democratic countries. Hence, countries whose income level is equal could experience different probabilities of a negative IER if their political systems are unequal. These results are in line with those obtained by Magnani (2000) who found that net effect of equality on her dependent variable (environmental expenditures) was positive. However, contrary to her results or those obtained by Harbaugh et al. (2002) we do not find evidence that suggests that the level of (political) equality is significant. Estimating specifications 4-5 including $P_{i t}$ does not result in a significant estimate for this variable.

The evidence supports the hypothesis that the level of environmental damage matters. The estimates of the terms involving our measure of concentration of the fixed effects logit model with the 5-year rule are all highly significant and negative. Estimates of the 10-year rule reveal that only the level of concentration is significant. For both random effects probit models, the level of concentration is never significant but the interaction terms are. This seems to suggest that higher levels of concentration predict a higher probability of a negative IER. For both 5-year rules and the random effects probit 10-year estimates, the impact of the level of concentration increases as a country is politically more open. These results could be seen as a reassertion of those obtained by Kaufmann et al. (1998), who found that the level of environmental damage plays a significant role in explaining the income-environment relationship. Our estimates suggest, with the exception of those for the 10-year rule fixed effects logit model, that demand for a better environment, due to a high level of environmental damage, is translated sooner into intervention in politically open and democratic societies.

Whether a country is politically open or not does, in itself, not have an impact on the probability of a downward sloping IER. Although the coefficient for the polity variable reported in column (3) in Tables 3, 4, A1 and A2 has the expected sign, it is hardly significant. With the exception of our estimates for the 10-year rule random effects probit model, the coefficient for $P_{i t}$ is never significant and even when it is, it is only so at the $10 \%$ level. Both EKC-rules offer the same result. However, as already discussed, when interacted with per capita income as well as with the level of concentrations, the polity variable has a significant impact for both models with the 5-year rule and for the random effects probit model with the 10-year rule. From these estimates, it follows that the political openness of a country is important as a way to translate popular demand for a better environment into policy intervention. The estimates suggest that one needs both for the probability of a negative IER to be affected. A democratic government in a country whose environment is extremely clean does not have to introduce legislation. Our estimates suggest that the probability that it will do so is indeed limited.
Economic openness is only significant and positive for the 10 -year rules. Both 5-year models reveal positive but insignificant estimates. The estimates for the 5-year rule are contrary to those obtained by, for instance, Harbaugh et al. (2002) or Cole (2004) whose evidence suggests that trade intensity is negatively associated with pollution. However, the estimates for the 10-year rule are positive and suggest that, at least over a 10-year period, that trade openness is positively associated with the probability of a negative IER. The probability of a negative IER over a 10-year time frame is higher in those countries that are more open to international trade.

\section{Final conclusions}

This paper uses a binary response model to analyse the probability that a particular country's IER is negative, i.e. that it has experienced a period within which environmental quality has improved with economic growth. The analysis suggests that it is an approach that might be worth exploring further. A binary response approach is less demanding compared to the traditional cross-section time series approach used in most of the EKC literature. Hence, it seems to offer a methodology that is able to serve as an alternative that suffers less from the critiques on the traditional approach. The evidence in this paper suggests that a binary response approach might be a good alternative to explore the characteristics of countries that have been developing along the downward sloping part of an EKC. In our implementation of the model, our estimates reveal an EKC-like relation between the probability that a country is experiencing better environmental quality and per capita GDP. The income turning points, although on the low end of previously reported results, are within the sample range. Our results show that controlling for environmental damage is important as the probability of a negative IER increases with the level of environmental damage. Our evidence further suggests that the impact of per capita income or the level of concentration is affected by the openness of the political structures in a country. For a given level of per capita income or concentration a more politically open country has a higher probability of experiencing a negative IER. This binary response model has disadvantages as well. First of all, it does not allow us to assess the irreversibility of environmental pollution at its peak. This shows that a binary response approach should not be seen as a substitute for other methodologies based on reduced form regressions. A second disadvantage of a binary response approach concerns the binary nature of the approach. A country is either developing along the downward sloping part or it is not. A binary response approach does not differentiate between countries whose slope is steep and those whose slope is down but rather flat. A multinomial approach might offer an alternative that allows us to distinguish between various 'levels of steepness' of the EKC.

However, a binary response model might be a valuable tool to gain a better understanding of the characteristics of those countries that have actually experienced periods where economic growth was not associated with higher levels of environmental pollution. 


\section{Acknowledgements}

The authors would like to thank Bruno Merlevede and one anonymous referee of this journal for useful comments and suggestions. Any remaining errors are exclusively ours.

\section{Appendix A}

\section{Table A1 - Estimates for the fixed effects logit model for the 10-year rule}

\begin{tabular}{|c|c|c|c|c|c|}
\hline & (1) & (2) & (3) & (4) & (5) \\
\hline Per capita GDP & $-17.2146[7.3639]^{* *}$ & $-51.9112[16.4457]^{* * *}$ & $-43.1936[15.5772]^{* * *}$ & $-38.5127[17.8910]^{* *}$ & $-50.0105[22.1075]^{* *}$ \\
\hline Per capita GDP sq. & $1.1141[0.4473]^{* *}$ & $3.124[0.9906]^{* * *}$ & $2.6505[0.9368]^{* * *}$ & $2.3685[1.0767]^{* *}$ & $2.8428[1.2858]^{* *}$ \\
\hline Concentration & & $-4.995[1.6634]^{* * *}$ & $-4.0669[1.5582]^{* * *}$ & $-3.9783[1.5148]^{* * *}$ & $-4.4289[1.6716]^{* * *}$ \\
\hline Polity & & & $0.1458[0.1770]$ & & \\
\hline Concentration *Polity & & & & $-0.0333[0.0930]$ & $-0.049[0.0984]$ \\
\hline Per capita GDP*Polity & & & & $0.0563[0.1131]$ & $0.0696[0.1170]$ \\
\hline Openness & & & & & $0.0935[0.0533]^{*}$ \\
\hline N. Obs. & 105 & 105 & 90 & 90 & 90 \\
\hline N. Groups & 35 & 35 & 31 & 31 & 31 \\
\hline Log likelihood & -33.1 & -16.43 & -14.48 & -14.43 & -12.55 \\
\hline Log likelihood c.o. & -38.45 & -38.45 & -32.84 & -32.84 & -32.84 \\
\hline$x^{2}$ & $10.71^{* * *}$ & $44.03^{* * *}$ & $36.73^{* * *}$ & $36.82^{* * *}$ & $40.59^{* * *}$ \\
\hline Pseudo- $R^{2}$ & 0.1039 & 0.4635 & 0.4499 & 0.4513 & 0.5044 \\
\hline Income turning point ${ }^{\mathrm{b}}$ & 2266 & 4058 & 3457 & 3395 & 6608 \\
\hline Polity $=+10$ & & & & n.s. ${ }^{c}$ & n.s. ${ }^{c}$ \\
\hline Polity $=-10$ & & & & n.s. ${ }^{c}$ & n.s. ${ }^{c}$ \\
\hline
\end{tabular}

a Dependent variable is the probability that the IER is negative over a 10 -year period. Column headings refer to the specification. Standard errors are reported between brackets. ${ }^{* * *},{ }^{* *}$ and ${ }^{*}$ denote significance at the $1 \%, 5 \%$ and $10 \%$ level.

b Income turning points are in 1985 USD.

c Estimate of the interaction terms in per capita GDP and Polity is not significant.

\section{Table A2 - Estimates from the random effects probit model for the 10-year rule}

\begin{tabular}{|c|c|c|c|c|c|}
\hline & (1) & (2) & (3) & (4) & (5) \\
\hline Per capita GDP & $-6.0013[1.5666]^{* * *}$ & $-6.3155[1.5918]^{* * *}$ & $-7.7056[1.8110]^{* * *}$ & $-6.6682[1.8757]^{* * *}$ & $-6.7837[1.8989]^{* * *}$ \\
\hline Per capita GDP sq. & $0.3953[0.0990]^{* * *}$ & $0.4085[0.1001]^{* * *}$ & $0.4864[0.1136]^{* * *}$ & $0.4186[0.1189]^{* * *}$ & $0.4251[0.1202]^{* * *}$ \\
\hline Concentration & & $-0.0779[0.0503]$ & $-0.0818[0.0567]$ & $-0.077[0.0572]$ & $-0.0356[0.0614]$ \\
\hline Polity & & & $0.0335[0.0176]^{*}$ & & \\
\hline Concentration ${ }^{*}$ Polity & & & & $-0.0106[0.0056]^{*}$ & $-0.0114[0.0056]^{* *}$ \\
\hline Per capita GDP*Polity & & & & $0.0145[0.0059]^{* *}$ & $0.0158[0.0060]^{* * *}$ \\
\hline Openness & & & & & $0.0045[0.0023]^{*}$ \\
\hline N. Obs. & 220 & 220 & 197 & 197 & 197 \\
\hline N. Groups & 74 & 74 & 71 & 71 & 71 \\
\hline Log likelihood & -102.69 & -101.48 & -86.51 & -84.42 & -82.48 \\
\hline Log likelihood c.o. & -113.84 & -113.84 & -103.01 & -103.01 & -103.01 \\
\hline$\chi^{2}$ & $22.3^{* * *}$ & $24.73^{* * *}$ & $33^{* * *}$ & $37.18^{* * *}$ & $41.05^{* * *}$ \\
\hline Pseudo- $R^{2}$ & 0.1012 & 0.1121 & 0.1669 & 0.1879 & 0.2074 \\
\hline Income turning point ${ }^{b}$ & 1980 & 2276 & 2755 & 2878 & 2919 \\
\hline Polity $=+10$ & & & & 3267 & 3338 \\
\hline Polity $=-10$ & & & & 2536 & 2553 \\
\hline
\end{tabular}

a Dependent variable is the probability that the IER is negative over a 10 -year period. Column headings refer to the specification. Standard errors are reported between brackets. ${ }^{* * *},{ }^{* *}$ and ${ }^{*}$ denote significance at the $1 \%, 5 \%$ and $10 \%$ level.

b Income turning points are in 1985 USD. 


\section{R E F E R E N C E S}

Arrow, K., Bolin, B., Costanza, R., Dasgupta, P., Folke, C., Holling, C.S., Jansson, B.-O., Levin, S., Mäler, K.-G., Perrings, C., Pimentel, D., 1995. Economic growth, carrying capacity, and the environment. Science 268 (April 28).

Aslanidis, N., Xepapadeas, A., 2003. Regime Switching and the Shape of the Emission-Income Relationship. Mimeo, University of Crete, Department of Economics.

Aslanidis, N., Xepapadeas, A., 2004. Smooth transition pollutionincome paths. Mimeo, University of Crete, Department of Economics.

Bertinelli, L., Strobl, E., 2005. The environmental Kuznets curve semi-parametrically revisited. Economics Letters 88, 350-357.

Cole, M., 2004. Trade, the pollution haven hypothesis and the environmental Kuznets curve: examining the linkages. Ecological Economics 48, 71-81.

Coondoo, D., Dinda, S., 2002. Causality between income and emission: a country group-specific econometric analysis. Ecological Economics 40, 351-367.

de Bruyn, S.M., van den Bergh, J.C.J.M., Opschoor, J.B., 1998. Economic growth and emissions: reconsidering the empirical basis of environmental Kuznets curves. Ecological Economics $25,161-175$.

Estrella, A., 1998. A new measure of fit for equations with dichotomous dependent variables. Journal of Business and Economic Statistics 16, 198-205.

Estrella, A., Mishkin, F.S., 1997. The predictive power of the term structure of interest rates in Europe and the United States: implications for the European Central Bank. European Economic Review 41, 1375-1401.

Folmer, H., de Zeeuw, A., 2000. International environmental problems and policy. In: Folmer, H., Gabel, H.L. (Eds.), Principles of Environmental and Resource Economics. Edward Elgar, Cheltenham, pp. 447-478.

Galeotti, M., Lanza, A., 2005. Desperately seeking environmental Kuznets. Environmental Modelling and Software 20, 1379-1388.

Grossman, G.E., Krueger, A.B., 1995. Economic growth and the environment. The Quarterly Journal of Economics CX (2), 353-377.

Halkos, G.E., Tsionas, E.G., 2001. Environmental Kuznets curves: Bayesian evidence from switching regime models. Energy Economics 23, 191-210.

Harbaugh, W., Levinson, A., Wilson, D., 2002. Re-examining the empirical evidence for an environmental Kuznets curve. The Review of Economics and Statistics 84, 541-551.

Heerink, N., Mulatu, A., Bulte, E., 2001. Income inequality and the environment: aggregation bias in environmental Kuznets curves. Ecological Economics 38, 359-367.

Holtz-Eakin, D., Selden, T.M., 1992. Stoking the fires? $\mathrm{CO}_{2}$ emissions and economic growth, NBER Working paper 4248.

Kaufmann, R.K., Davidsdottir, B., Garnham, S., Pauly, P., 1998. The determinants of atmospheric $\mathrm{SO}_{2}$ concentrations: reconsidering the environmental Kuznets curve. Ecological Economics 25, 209-220.

Lee, J., List, J.A., 2004. Examining trends of criteria air pollutants: ere the effects of government intervention transitory? Environmental and Resource Economics 29, 21-37.

Lefohn, A.S., Husar, J.D., Husar, R.B., 1999. Estimating historical anthropogenic global sulphur emission patterns for the period 1850-1990. Atmospheric Environment 33, 3435-3444.
Lieb, C., 2004. Possible Causes of the Environmental Kuznets Curve. Peter Lang AG, Bern. 276 pp.

List, J.A., Gallet, C.A., 1999. The environmental Kuznets curve: does one size fit all? Ecological Economics 31, 409-423.

Maddala, G.S., 1987. Limited Dependent Variable Models Using Panel Data. The Journal of Human Resources 22, 307-338.

Magnani, E., 2000. The environmental Kuznets curve, environmental protection and income distribution. Ecological Economics 32, 431-443.

Marshall, M.G., Jaggers, K., 2000. Polity IV project: Political Regime Characteristics and Transitions, 1800-1999, Dataset Users Manual, University of Maryland. 94 pp.

Moomaw, W.R., Unruh, G.C., 1997. Are Environmental Kuznets curves misleading us? The case of $\mathrm{CO}_{2}$ emissions. Environment and Development Economics 2, 451-463.

Nelson, C., Plosser, C., 1982. Trends and random walks in macroeconomic time series: some evidence and implications. Journal of Monetary Economics 10, 130-162.

Panayotou, T., 2000. Economic growth and the Environment. CID Working Paper No. 56.

Perman, R., Stern, D.I., 2003. Evidence from panel unit root and cointegration tests that the Environmental Kuznets Curve does not exist. The Australian Journal of Agricultural and Resource Economics 47, 325-347.

Ravallion, M., Heil, M., Jalan, J., 2000. Carbon emissions and income inequality. Oxford Economic Papers 52, 651-669.

Selden, T.M., Song, D., 1994. Environmental quality and development: is there a Kuznets curve for air pollution emissions. Journal of Environmental Economics and Management 27, 147-162.

Shafik, N., 1994. Economic development and environmental quality: an econometric analysis. Oxford Economic Papers 46, 757-773.

Smulders, S., Bretschger, L., 2001. Explaining Environmental Kuznets Curves: How Pollution Induces Polity and New Technologies. Mimeo, Tilburg University, Tilburg.

Stern, D.I., 1998. Progress on the environmental Kuznets curve? Environment and Development Economics 3 (2), 173-196.

Stern, D.I., 2005. Beyond the environmental Kuznets curve: diffusion of sulphur-emissions-abating technology. Journal of Environment and Development 14, 101-124.

Stern, D.I., Kaufmann, R.K., 1999. Econometric analysis of global climate change. Environmental Modelling and Software 14, 597-605.

Stern, D.I., Common, M.S., 2001. Is there an environmental Kuznets curve for sulphur? Journal of Environmental Economics and Management 41, 162-178.

Summers, R., Heston, A., 1994. The Penn World Tables (mark 5.6), dataset.

Suri, V., Chapman, D., 1998. Economic growth, trade and energy: implication for the environmental Kuznets curve. Ecological Economics 25, 195-208.

Torras, M., Boyce, J.K., 1998. Income, inequality, and pollution: a reassessment of the environmental Kuznets Curve. Ecological Economics 25, 147-160.

Verbeke, T., De Clercq, M., in press. The EKC: some really disturbing Monte Carlo evidence, Environmental Modelling and Software. 